\title{
An inferior sinus venosus interatrial communication associated with a secundum atrial septal defect, clinically presenting in an adult patient: autopsy report
}

\author{
Silvana Maria Lovisolo ${ }^{a}$, Vera Demarchi Aiello ${ }^{b}$, Fernando Peixoto Ferraz de Campos ${ }^{c}$
}

Lovisolo SM, Aiello VD, Campos FPF. An inferior sinus venosus interatrial communication associated with a secundum atrial septal defect, clinically presenting in an adult patient: autopsy report. Autopsy Case Rep [Internet]. 2011;1(4):21-27. http://dx.doi.org/10.4322/acr.2011.013

\section{ABSTRACT}

\begin{abstract}
Atrial septal defects (ASD) are the most common congenital cardiac lesion in adults, representing up to $40 \%$ of acyanotic shunt lesions in patients older than 40 years. Secundum ASD comprises defects in the area of the oval fossa, and may be associated with other types of interatrial communications. We present a case of a 25 year-old female patient who was asymptomatic until the age 22 when she started presenting exertion dyspnea and lower limbs edema, during her third pregnancy. The patient was admitted in the emergency department because of a febrile respiratory distress syndrome dying in less than 36 hours after her arrival. The autopsy examination revealed pneumonia and a secundum ASD, associated with a rare form of interatrial communication, the inferior sinus venosus defect, which is characterized by an anomalous connection of the right pulmonary veins to the inferior caval vein at its opening in the right atrial cavity, while retaining partially their connection to the left atrium. A dysplastic and thickened mitral valve was also present. Signs of pulmonary hypertension confirm the Eisenmenger syndrome in this adult patient.
\end{abstract}

Keywords: Congenital heart defects; Atrial septal defect sinus venosus; Heart septal defects; Atrial; Pulmonary hypertension; Pneumonia; Autopsy.

\section{CASE REPORT}

A 25 year-old female patient sought the emergency department complaining of dyspnea and cough for several months aggravated in the last three days when she began to present purulent sputum with bloody traces and daily fever of $38^{\circ} \mathrm{C}$. She had been presenting progressive dyspnea, orthopnea, increased abdominal volume and edema of lower limbs for the last three years. She started looking for medical care one year after the initial symptoms when a cardiopathy was diagnosed and a heart surgery indicated at her local State of origin, but not performed due to the delay in scheduling. The patient lived in the interior of a northeastern state of Brazil far from a tertiary hospital. She denied any morbidity or physical limitation during childhood and adolescence. Her obstetrical history included

\footnotetext{
${ }^{a}$ Anatomic Pathology Service - Hospital Universitário, Universidade de São Paulo, São Paulo/SP - Brazil.

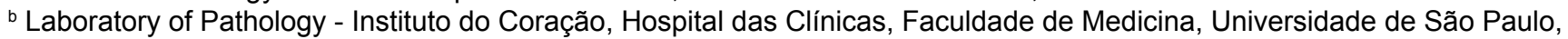

São Paulo/SP - Brasil.

c Department of Internal Medicine - Hospital Universitário, Universidade de São Paulo, São Paulo/SP - Brazil.
}

Copyright $\odot 2011$ Autopsy and Case Reports - This is an Open Access article distributed of terms of the Creative Commons Attribution NonCommercial License (http://creativecommons.org/licenses/by/3.0/) which permits unrestricted non-commercial use, distribution, and reproduction in any médium provided article is properly cited. 
three pregnancies and the symptoms began during the last gestation. On admission the patient was agitated, confused, presenting dyspnea, tachycardia, cyanosis, and was emaciated. Vital signs were: respiratory rate $=27 \mathrm{bpm}$, pulse rate $=120 \mathrm{bpm}$, blood pressure $=96 \times 60 \mathrm{mmHg}$, temperature $=35.5^{\circ} \mathrm{C}$, oximetry $=65 \%$. The pulmonary auscultation revealed the presence of rales in the left base, the precordium examination showed systolic thrill on the left sternal border. The cardiac sounds were rhythmic with loud S2, S3 present and a marked murmur was audible on the tricuspid area. The abdominal examination showed hepatomegaly and percussion was dull on the Traube's space. Lower limb edema was present. Laboratory tests are shown in Table 1 and the electrocardiogram in Figure 1. The patient was initially treated with oxygen by Venturi mask followed by endotracheal intubation and mechanical ventilation, ceftriaxone and clarithromycin were prescribed considering the possibility of pneumonia. The hemodynamic instability was treated with saline volume expansion followed by intravenous vasoactive drugs. Despite the adopted treatment the patient died on the second day of hospitalization. An echocardiogram performed on admission with the patient on sitting position showed: aorta $=28 \mathrm{~mm}$, left atrium $=30 \mathrm{~mm}$, ventricular septum $=8 \mathrm{~mm}$, posterior wall $=7 \mathrm{~mm}$, left ventricle ejection fraction $=60 \%$. There was also significant increase in the size of the right atrium and ventricle, hypokinetic right ventricle, mitral valve degeneration with prolapse and mild regurgitation, tricuspid valve reflux with important right ventricle-right atrium pressure gradient $=140 \mathrm{mmHg}$. The blood sample collected at admission showed growth of Streptococcus pneumoniae.
The autopsy findings showed an emaciated woman with signs of growth impairment, mild cyanosis and lower limb edema.

The heart was enlarged, weighed $702 \mathrm{~g}$ (normal range, 248-431 g), and showed usual atrial arrangement, with concordant atrioventricular and ventriculo-arterial connections. There was massive enlargement of the right-sided cardiac chambers, with severe dilation and hypertrophy of the right ventricle.

Examining the right atrial septal surface we detected a huge ASD located in the area of the oval fossa (secundum atrial septal defect). There was also an additional interatrial communication situated postero-inferiorly, close to the opening of the inferior caval vein into the right atrium, and where the right pulmonary veins were connected (Figures $2 a$ and $2 b)$. These veins retained, partially, their connection to the postero-inferior wall of the left atrium.

The left atrium was small, receiving also the two left pulmonary veins, which were far from the sinus venosus defect. The mitral valve showed moderate thickening of the leaflets, mainly the anterior one, besides fusion of the postero-medial comissure and thick chordae. The left ventricle was normal in size.

A schematic view of the heart with the anomalous connection of the right pulmonary veins and with a secundum atrial septal defect is exemplified in Figure 3.

The right and left lungs weighed 935 and $850 \mathrm{~g}$ respectively (normal range, 360-570

Table 1 - Laboratory analysis on admission

\begin{tabular}{|c|c|c|c|c|c|c|c|}
\hline Exam & Un. & Result & Ref.V & Exam & Um. & Result & Ref.V \\
\hline Hemoglobin & g.dL & 14,8 & $12,3-15,3$ & $\mathrm{RCP}$ & $\mathrm{ng} \cdot \mathrm{mL}^{-1}$ & 334 & $<5$ \\
\hline Hematocrit & $\%$ & 47 & $36,0-45,0$ & Creatinine & $\mathrm{mg} \cdot \mathrm{dL}^{-1}$ & 1,0 & $0,4-1,3$ \\
\hline Leukocytes & $\mathrm{mm}^{3}$ & 3600 & $4,4-11,3.10^{3}$ & BUN & $\mathrm{mg} \cdot \mathrm{dL}^{-1}$ & 78 & $10-50$ \\
\hline $\begin{array}{l}\text { Metamyelocytes } \\
\text { bastonetes } \\
\text { segmentados }\end{array}$ & $\begin{array}{l}\% \\
\% \\
\%\end{array}$ & $\begin{array}{c}2 \\
21 \\
65\end{array}$ & $\begin{array}{c}0 \\
1-5 \\
45-70\end{array}$ & Lactate & $\mathrm{mg} \cdot \mathrm{dL}^{-1}$ & 46,1 & $4,5-19,8$ \\
\hline Eosinophils & $\%$ & 0 & $1-4$ & AST & U. $L^{-1}$ & 97 & $10-31$ \\
\hline Basophils & $\%$ & 0 & $0-2,5$ & ALT & U. $L^{-1}$ & 35 & $9-36$ \\
\hline Linfocytes & $\%$ & 8 & $18-40$ & $\begin{array}{c}\text { Protrombine } \\
\text { T (INR) }\end{array}$ & & 1,98 & 1 \\
\hline Monocytes & $\%$ & 4 & $2-9$ & $\mathrm{pH}$ & & 7,14 & $7,34-7,44$ \\
\hline Platelets & $/ \mathrm{mm}^{3} \mathrm{~m}^{3}$ & 2110000 & $150-400.10^{3}$ & $\mathrm{HCO}_{3}$ & $\mathrm{mEq} \cdot \mathrm{L}^{-1}$ & 15 & $22-26$ \\
\hline
\end{tabular}

Un. = unit, Ref.V = reference value, $\mathrm{RCP}=$ reactive $\mathrm{C}$ protein, $\mathrm{BUN}=$ blood urea nitrogen, $\mathrm{AST}=$ aspartate transaminase, $\mathrm{ALT}=$ alanine transaminase . 
and $325-480 \mathrm{~g}$ ). The microscopic examination revealed diffuse infiltration of neutrophils filling the alveolar spaces accompanied by hemorrhagic and edematous areas with considerable destruction of alveolar septa (Figure 4) configuring the histological picture of bronchopneumonia; and thickening of the fibromuscular layer of the pre and intra-acinar peripheral pulmonary arteries (Figure 5) representing chronic pulmonary hypertension.

The liver weighed $1560 \mathrm{~g}$ (normal range 1330$2100 \mathrm{~g}$ ) and showed chronic passive congestion compatible with right sided heart failure, and peri-central hemorrhagic foci due to septicemia and shock.

Systemic findings of sepsis and shock were also observed in other organs as acute reactive splenitis, renal tubular acute necrosis and hemorrhagic foci of cortical adrenal glands.

The gross and microscopic examinations of the other organs were unremarkable.

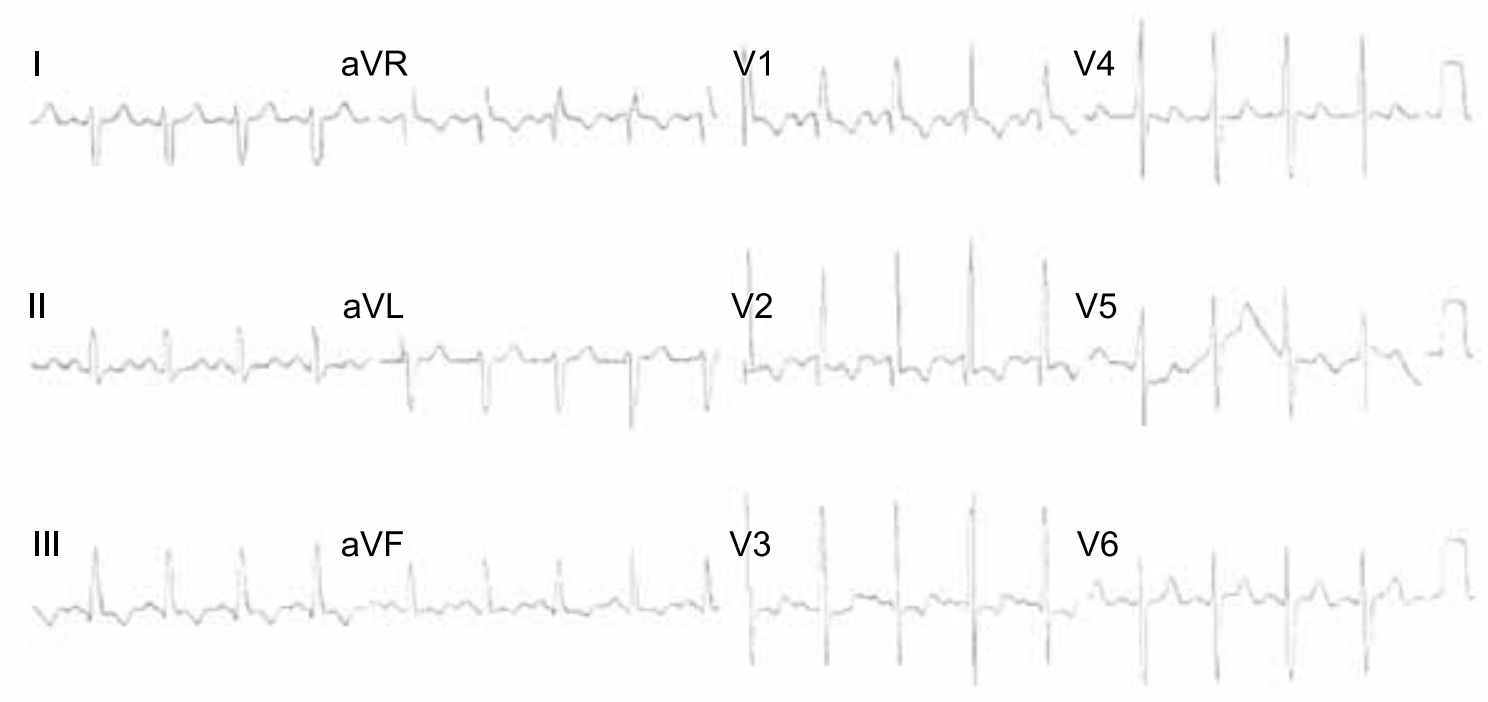

II

Figure 1 - Electrocardiogram showing sinus rhythm, heart $=120 \mathrm{bpm}, \mathrm{PRi}=0,16 \mathrm{~m} \cdot \mathrm{s}^{-1}$, QRS axis $+120^{\circ}$, rSr' morphology compatible with right ventricle hypertrophy, and signs of left atrium enlargement ( $p$ wave negative in V1).
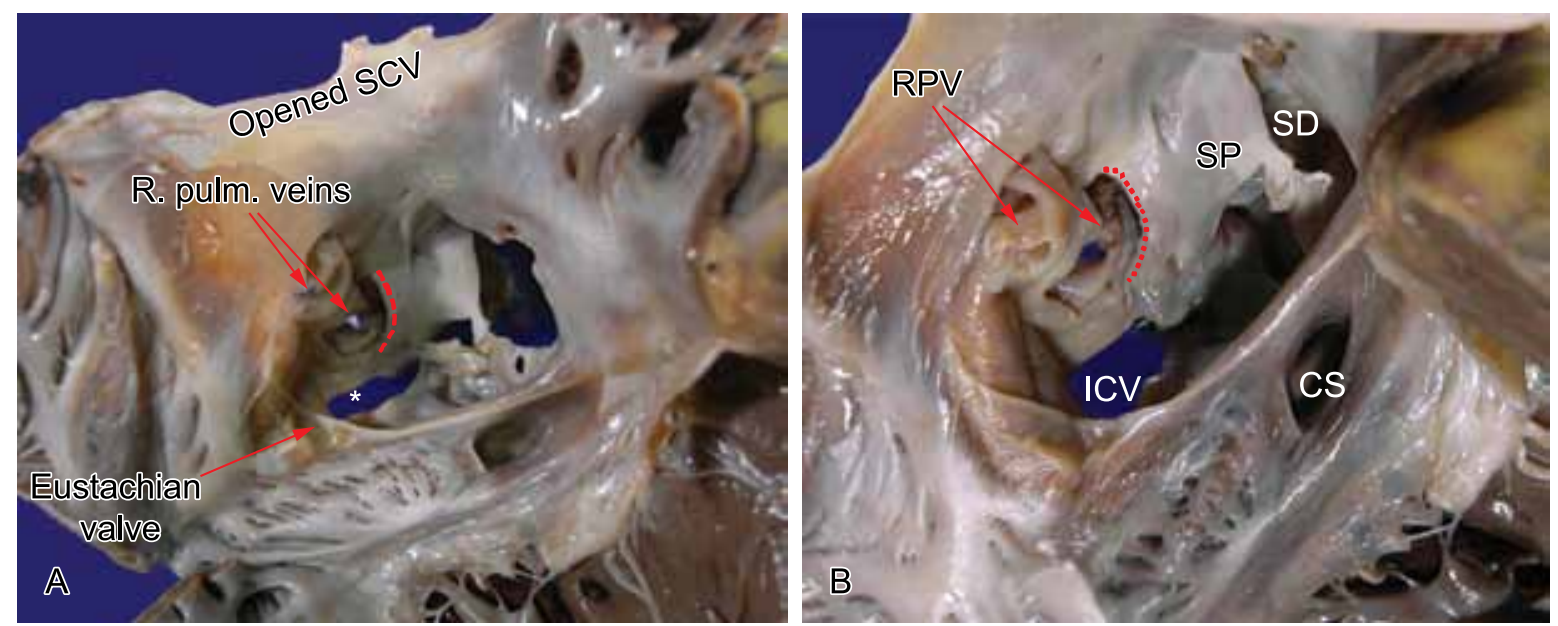

Figure 2 - Septal surface seen from the right atrium showing the abnormal insertion of the RPV at the mouth of the ICV and the interatrial communication which inferior border is marked by the dotted line. In B panel a closer view depicts the opening of the RPV. (RPV = right pulmonary veins; ICV = inferior caval vein; $\mathrm{CS}=$ coronary sinus; $\mathrm{SD}=$ secundum defect, in $\mathbf{A}^{*}$ shows the opening o ICV. 

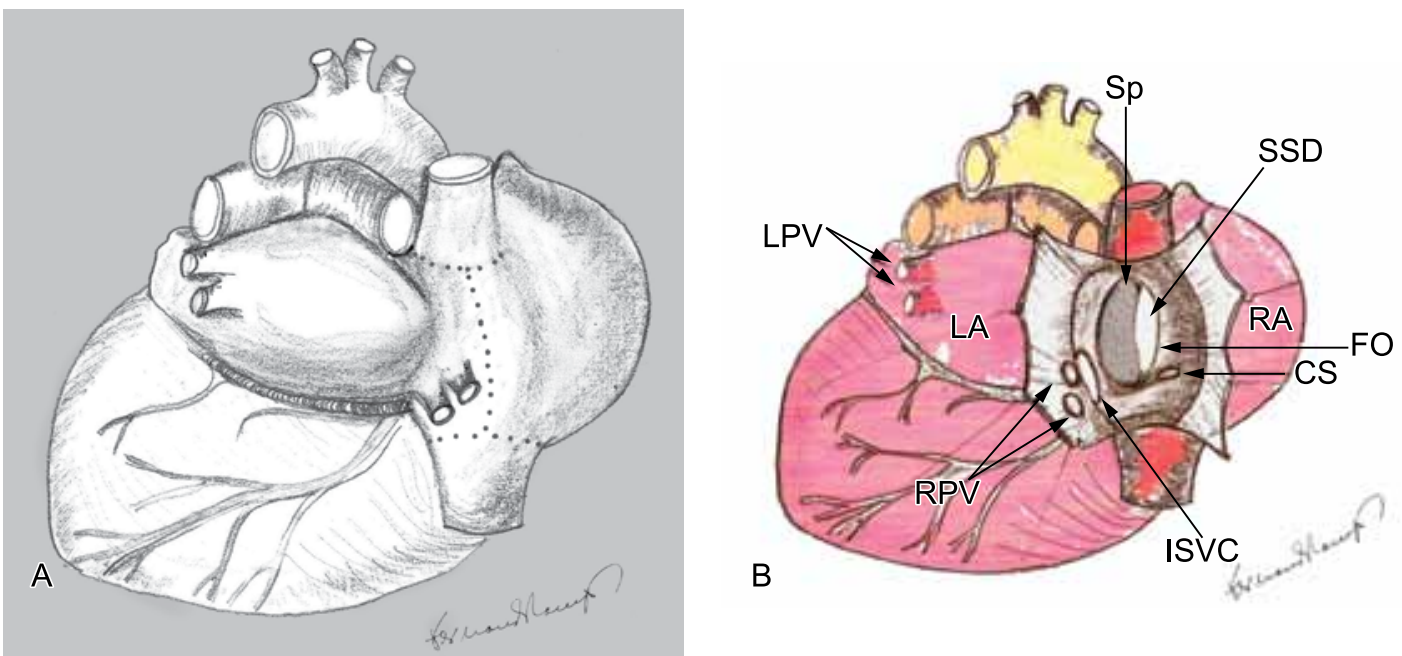

Figure 3 - Schematic posterior view of the heart showing in $\mathbf{A}$ the anomalous implantation of the right pulmonary veins close to the openning of the inferior caval vein. The dotted line shows where the right atrium was opened to demonstrate the inner structures; in B an opened view by the posterior wall of the right atrium depicting the inferior sinus venosus interatrial communication, the secundun atrial septal defect. $\mathrm{RA}=$ right atrium; LA = left atrium; RPV = right pulmonar veins; LPV = left pulmonar veins; CS = coronary sinus; SSD = secundum septal defect $; \mathrm{Sp}=$ septum primum, $\mathrm{FO}=$ fossa ovale.

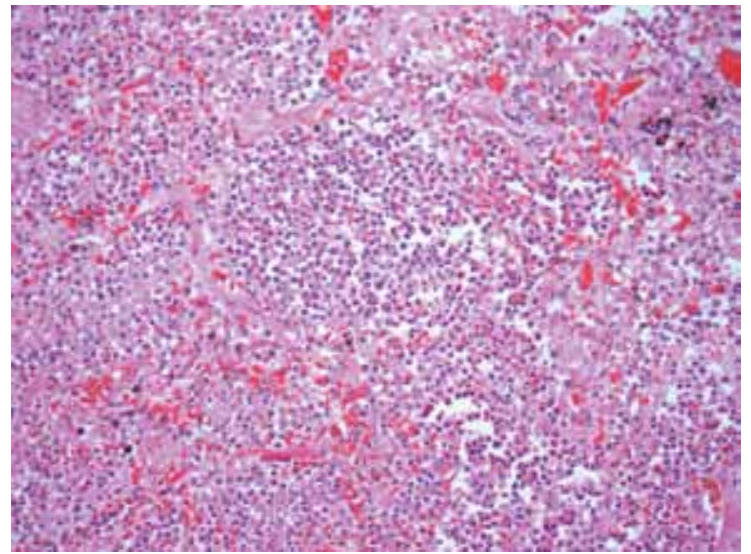

Figure 4 - Photomicrography of the lung showing massive neutrophilic infiltration of the alveolar spaces, edema, haemorrhagic focci and destruction of alveolar septa (H\&E stain, objective magnification $-10 \mathrm{X})$.

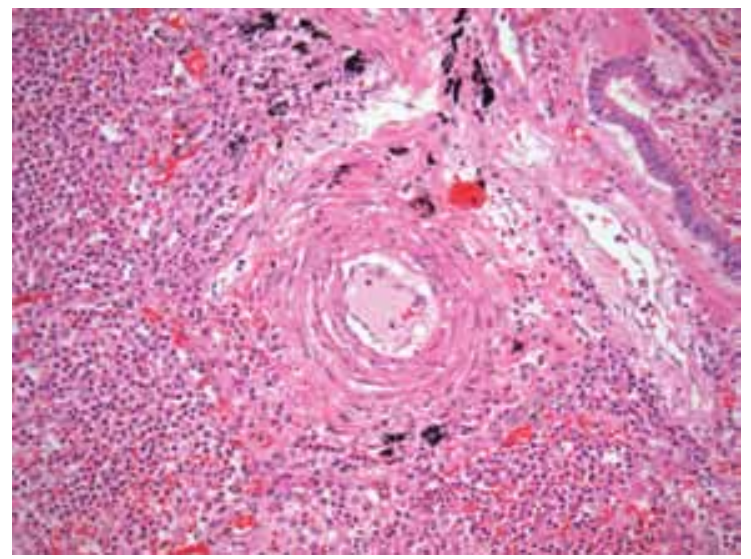

Figure 5 - Photomicrography of the lung with depicting a pre-acinar pulmonary artery with thickening of the medial layer (H\&E stain, objective magnification - 20X).

\section{DISCUSSION}

Atrial septal defects (ASD) are the most common congenital lesion in adults after bicuspid aortic valve, ${ }^{1-3}$ representing up to $40 \%$ of acyanotic shunt lesions in patients older than 40 years. ${ }^{4}$

Although the defect is often asymptomatic until adulthood, potential complications of an undetected ASD include right ventricular failure, atrial arrhythmias, and pulmonary hypertension that can become irreversible and lead to right-to-left shunting (Eisenmenger syndrome) as was observed in the case related here. ${ }^{1}$

Secundum ASD comprises defects in the area of the oval fossa. This type of ASD accounts for 70 to $75 \%$ of all interatrial communications and is more common in females. ${ }^{5,6}$ They may be associated with or other interatrial communications, such as a sinus venosus defect or an ostium primum defect in the context of an atrioventricular septal defect. Mitral valve prolapse is present in up to $70 \%$ of patients with secundum ASD. ${ }^{1}$

The patient here reported presented a secundum ASD associated with a rare form of congenital anomaly, the inferior sinus venosus defect. While the defects within the confines of the oval fossa are considered true septal defects, those located close to the openings of the caval veins are not. In this regard, we should emphasize that the recognition of the true atrial septal structures is 
based on the fact that they represent part of the atrial wall that when removed does not allow access to the extracardiac space. Only the floor of the oval fossa (flap valve) and its antero-inferior rim do fill this criterion. On the other hand, its superior rim, the socalled septum secundum, represents a deep infolding of the adjacent atrial walls filled with extracardiac fat tissue.

Due to their location far from the true atrial septum, the sinus venosus defects should be better designated as interatrial communications, the same way as the so-called coronary sinus defects, which are the consequence of partial or total absence of the coronary sinus wall separating this venous channel from the left atrium. ${ }^{7}$

The commonest form sinus venosus defect is the superior variant, usually accompanied by an overriding superior caval vein over the superior rim of the oval fossa and anomalous insertion of the right pulmonary veins. ${ }^{8}$

The inferior variant of sinus venosus defects has not been so-well recognized clinically and by echocardiography. From the morphological point of view, on the other hand, it is clear that the essence of the malformation is an anomalous venoatrial connection of the inferior caval vein and pulmonary veins, in continuity with the walls of both the right and left atriums, thus allowing interatrial shunting. ${ }^{9}$ The differential diagnosis with a true secundum septal defect extending posteroinferiorly to the opening of the inferior caval vein is based on the absence of the posterior rim of the oval fossa in this situation, while in the inferior sinus venosus defect that rim is intact.

In the case reported here, the combined area for interatrial shunting (ASD and sinus venosus defect) was large, not restrictive, and resulted in an increased pulmonary blood flow with development of pulmonary hypertension which became symptomatic early in the adult life.

Most children and adolescents with an ASD, particularly an isolated secundum ASD, are asymptomatic even in the presence of large shunts. ${ }^{1}$ In a review of 481 patients with a secundum ASD were seen between 1957 and 1976 who underwent surgical correction before the age of 40 , the defect was discovered on routine examination in $202(42 \%){ }^{10}$ In comparison, patients who present in infancy, particularly with heart failure and/or failure to thrive, usually have associated cardiac defects. ${ }^{11}$
Although our patient evolved to irreversible pulmonary hypertension early in her adult life, she carried out two asymptomatic pregnancies never presenting any disability during infancy and adolescence.

We dare to conclude, in this case, that the inferior sinus venosus interatrial communication in itself did not alter significantly the natural history of the Secundum ASD once the latter was large.

At present there are few studies of large numbers of patients with inferior sinus venosus defect based on anatomic diagnosis during life. Crystal et al. identified 11 children with median age of 1,2 years, who were clinically non cyanotic and presented with normal pulse rate and blood pressure. All children had normal jugular venous pulsation and none presented respiratory distress. As expected all children demonstrated a widely split second heart sound, a systolic ejection murmur was identified and a right ventricular heave was palpable in $5 / 11$ patients. ${ }^{9}$ These findings show that isolated inferior sinus venosus interatrial communication create a left to right shunt clinically identifiable and with no signs of decompensate heart failure at this age. In the series of Banka et al, 45 patients with the diagnosis of ISVD were referred for surgery. These patients were younger than the overall group with isolated interatrial defects, possibly reflecting a greater degree of shunting demanding early surgical repair. ${ }^{12}$

The hemodynamic abnormality is the same in the two instances in which there is shunting between the atriums; therefore we believe that the association of both abnormalities presented the natural history of a non restrictive large ASD.

When large, the defect does not restrict flow, there is no or nearly no pressure gradient between the atria and functionally the two atria can be regarded as a common chamber. The proportions of flow out of this common chamber will be determined by which ventricle is most easily filled, thus the ventricular diastolic properties are of paramount importance in this context. ${ }^{13,14}$ The increase in left-to-right shunting with age in many patients with uncorrected moderate to large ASDs increases the likelihood of developing symptoms. It is estimated that most patients with an ASD with significant shunt flow will be symptomatic and will require surgical correction by the age of $40 .{ }^{10}$

The development of severe irreversible pulmonary hypertension or Eisenmenger syndrome (irreversible pulmonary hypertension at near systemic 
levels and reversal of shunt flow to a predominantly right-to-left direction) is now uncommon because of surgical or percutaneous correction of the defect. However, there may be an appreciable lifetime incidence of severe pulmonary hypertension in unoperated ASDs, with some older estimates being in the range of $50 \%$ as was observed in the case of this report. Although Eisenmenger syndrome is much less common with ASDs than with ventricular septal defects, ASDs have been a common cause of the syndrome because of their greater prevalence. ${ }^{15}$ The prognosis is relatively poor once Eisenmenger physiology has been established.

In the case reported here the symptoms started at the age of 22 and worsened during her third pregnancy. The patient lived in an area of poor medical resources; she did not look for pre natal consultations, if so she could have had the chance to be diagnosed earlier. Even when the diagnosis was made she was not operated, reflecting the discrepancies of the medical attention in different regions of Brazil.

\section{CONCLUSION}

Atrial septal defects are common congenital anomalies in adults and may be forgotten as a cause of congestive heart failure. Early recognition may help the patients to have normal survival by means of early surgical repair. The operative management in the case reported here would include, besides the defect closure, the transference of the right pulmonary veins to the left atrium.

\section{ACKNOWLEDGEMENTS}

We are grateful to Rosa Maria C. Zanardi for the technical support on the visual work of the images presented in this case.

\section{REFERENCES}

1. Wiegers SE, Sutton MGSJ. Management of atrial septal defects in adults. Waltham: UpToDate; 2011 [cited 2011 Oct 31]. Available from: http://www.uptodate.com/contents/ pathophysiology-and-clinical-features-of-atrial-septaldefects-in-adults?source=search_result\&search=interat rial+communication\&selectedTitle $=3 \sim 150$

2. Dickinson DF, Arnold R, Wilkinson JL. Congenital heart disease among 160,480 liveborn children in Liverpool 1960-1969, implications of surgical treatment. Br Heart J 1981; 46(1):5562. http://dx.doi.org/10.1136/hrt.46.1.55

3. Rosas M, Attie F, Sandoval J, et al. Atrial septal defect in adults $\geq 40$ years old: negative impact of low arterial oxygen saturation. International J Cardiol. 2004; 93(2):145-55. http://dx.doi.org/10.1016/S0167-5273(03)00192-X

4. Therrien J, Webb G. Clinical update on adults with congenital heart disease. Lancet. 2003;362(9392):1305-13. http:// dx.doi.org/10.1016/S0140-6736(03)14574-6

5. Webb G, Gatzoulis MA. Atrial septal defects in the adult: recent progress and overview. Circulation. 2006; 114(15):164553. PMid:17030704. http://dx.doi.org/10.1161/ CIRCULATIONAHA.105.592055

6. Shah D, Achar M,Oakley CM, Cleland JG, Nihoyannopoulos $P$. Natural history of secundum atrial septal defect in adults after medical or surgical treatment: a historical prospective study. Br Heart J. 1994; 71(3):224-7. http:// dx.doi.org/10.1136/hrt.71.3.224

7. English RF, Anderson RH, Ettedgui JA. Interatrial communications. In: Anderson RH, Baker EJ, Penny DJ, Redington AN, Rigby ML, Wernovsky G, editors. Paediatric cardiology. 3rd ed. Philadelphia: Elsevier; 2009. p. 523-46.

8. Al Zaghal AM, Li J, Anderson RH, Lincoln C, Shore D, Rigby ML. Anatomical criteria for the diagnosis of sinus venosus defects. Heart. 1997; 78(3):298-304. PMid:9391294. PMCid:484934.

9. Crystal MA, Najashi KA, Williams WG, Redington AN, Anderson $\mathrm{RH}$. Inferior sinus venosus defect: echocardiographic diagnosis and surgical approach. J Thorac Cardiovasc Surg. 2009; 137(6):1349-55. PMid:19464447. http://dx.doi. org/10.1016/j.jtcvs.2008.12.010

10. Rostad H, Sörland S. Atrial septal defect of secundum type in patients under 40 years of age. A review of 481 operated cases. Symptoms, signs, treatment and early results. Scand J Thorac Cardiovasc Surg. 1979; 13(2):1237. http://dx.doi.org/10.3109/14017437909100977

11. Manning PB, Mayer Junior JE, Sanders SP, et al. Unique features and prognosis of primum ASD presenting in the first year of life. Circulation. 1994; 90(5PT 2):II30-5.

12. Banka P, Bacha E, Powell AJ, Benavidez O, Geva T. Outcomes of inferior sinus venosus defect repair. J Thorac Cardiovasc Surg. 2011; 142(3):517-22. http://dx.doi. org/10.1016/j.jtcvs.2011.01.031

13. Rowe GG, Castillo CA, Maxwell GM, Clifford JE, Crumpton CW. Atrial septal defect and the mechanism of shunt. Am Heart J. 1961; 61:369-74. http://dx.doi.org/10.1016/00028703(61)90608-1

14. Weldon CS. Hemodynamics in acute atrial septal defect. Arch Surg. 1966; 93(5):724-9. PMid:5921293.

15. Waddell TK, Bennett L, Kennedy R, et al. Heart-lung or lung transplantation for Eisenmenger syndrome. J Heart Lung Transplant. 2002; 21(7):731-7. http://dx.doi.org/10.1016/ S1053-2498(01)00420-X 


\section{Conflict of interest: None}

Submitted on: $3^{\text {rd }}$ November 2011

Accept on: $21^{\text {st }}$ November 2011

Correspondence: Serviço de Anatomia Patológica

Av. Prof. Lineu Prestes, 2565 - Cidade Universitária - São Paulo/SP - Brazil

CEP: 05508-900 - Phone: +55 (11) 3091-9384

E-mail: slovisolo@hu.usp.br 